\title{
COMPARISON OF DIFFERENT COMPUTATIONAL METHODS FOR WATER STRUCTURE OPTIMISATION
}

\author{
${ }^{I}$ Staník, R. $-{ }^{2}$ Ballo, P. $-{ }^{1}$ Benkovský, I. \\ ${ }^{1}$ Comenius University, Bratislava, Faculty of Pharmacy, Department of Pharmaceutical \\ Analysis and Nuclear Pharmacy, \\ ${ }^{2}$ Slovak University of Technology, Department of Physics, Faculty of Electrical \\ Engineering and Information Technology
}

\begin{abstract}
We have compared several computational techniques with the aim to compute the radial distribution function (RDF) as a good characterization of water structure. In particular, we have used molecular mechanic (AMBER99), semi-empirical (AM1, PM3, PM6) and ab initio (DFT) technique. It has been shown that molecular mechanic gives very poor results in the case of water RDF. Ab initio techniques which are in general accepted as very exact methods, in the case of water underestimate intermolecular interaction. Unexpectedly, the semi-empirical method with PM6 parameterisation gives the best results in comparison with RDF measured by X-ray scattering experiment.
\end{abstract}

Keywords: water simulation - RDF - PM6 - DFT

\section{INTRODUCTION}

Water plays a fundamental role in the nature and continues to be in the focus of many scientists (Guillot et al., 2002). Water as a solvent can affect the drug interaction, the stability and formation of ionic compounds, spectroscopic properties and spatial conformation of molecules (Zhang et al., 2010, Azam et al., 2010, Woods et al., 2010, Hugosson et al., 2006, Cordeiro et al., 2006, Garrido et al., 2010). Perhaps, as the most common solvent in the nature is essential for human being. The properties of water, like the heat of vaporisation, the self diffusion coefficient, the atom-atom pair distribution function, the temperature of maximum density, the critical parameters, the dielectric constant and many others have been intensively studied by physical experiments as well as computer simulations (Sorenson et al., 2000, Campo, 2010, Head-Gordon, 2002, Tunon et al. 1996).

The choice of a computational technique plays an essential role in all numerical experiments. Today we have many possibilities - from fast and simple to exact and computational demanding techniques. The simple ones, like molecular mechanics enable 
to calculate only rudimentary properties for basic systems. Semi-empirical methods represent a "middle road" between the mostly qualitative results available from molecular mechanics and the computationally time-consuming quantitative results available from $a b$ initio. Quantum mechanics approach provides the most accurate results at the price of extensive computational time demand (Ramachandra et al., 2008). The availability of full-blown computers which increased during last few decades gives good chance to perform $a b$ initio calculation from hundreds to thousand atoms. An alternative possibility to reach a reliable description of the structure and properties of the system is to apply combined quantum mechanics/molecular mechanics (QM/MM) method (Intarathep et al., 2006).

In order to quantify the level of accuracy reached by different computational approaches, it is necessary to compare simulated water properties with experimental results. Radial distribution function (RDF) is usual output of computer simulations studies and it is typical characteristic of fluids in the statistical mechanic theories. In particular, RDF $g_{O O}(r)$ gives the information about oxygen-oxygen, $g_{O H}(r)$ about oxygen-hydrogen and $g_{H H}(r)$ about hydrogen-hydrogen density variation. RDF (Bandad et al. 2006, Kuhne et al., 2009).

The aim of this paper is to compare different computational methods with the goal to optimize the structure of water. In the present study, we have employed molecular mechanic (MM) implemented in HyperChem7.51 (HyperChem ${ }^{\mathrm{TM}}$ Profesional 7.51), semiempirical approach implemented in MOPAC9 (Molecular Orbital Package) (MOPAC 2009) and ab initio DFT method implemented in SIESTA (SIESTA code, 1996) (Spanish Initiative for Electronic Simulations with Thousands of Atoms).

\section{COMPUTATIONAL METHODS}

Three basic computational methods have been used in the particular investigation. We have performed the accuracy of molecular mechanic (AMBER99 force field) (Cornell et al., 1995), semi-empirical (AM1, PM3, PM6 parameterization)(Dewar et al., 1985, Stewart, 1989, Stewart, 2007) and ab initio (DFT) calculation applied to water optimization. Input entry of water molecules in various cubic boxes has been generated by HyperChem 7.51. In particular, we have used cubic box with a site length of $8.5 \AA$ (contains 21 water molecules), $10.0 \AA$ (33 water molecules), $11.0 \AA$ (43 water molecules), $12.0 \AA$ (51 water molecules) and $15.0 \AA$ (109 water molecules). In this paper, we will refer water clusters containing 21 and 33 individual molecules as small and water clusters containing 43, 51 and 109 water molecules as large.

Molecular mechanics (MM) uses analytical, differentiable and relatively simple potential energy function for describing the interactions between a set of atoms. We have used AMBER99 force field integrated in the program HyperChem 7.51. This force field was originally developed for computations of proteins and nucleic acids and contains parameters for bonded and non-bonded (electrostatic and Van der Waals) interactions among atoms (Ponder et al., 2003, Perez et al., 2007). It should be noted that Van der Waals interaction forms crucial forces of hydrogen bond. The interaction gives important part of all simulations with water. Furthermore, force fields for MM could have a specific 
hydrogen bonding term to improve the accuracy of water interactions (e.g. original AMBER force field). AMBER99 does not contain the specific hydrogen bonding term and Van der Waals interactions are accounted by normal electrostatic interaction.

Semi-empirical program MOPAC9 has been used as the second and more precise computational method. Water models were optimised by AM1 (Austin Model 1) (Dewar et al., 1985), PM3 (Parameterized Model 3) (Stewart, 1989) and PM6 (Parameterized Model 6) (Stewart, 2007). All techniques were implemented with MNDO model (Modified Neglect of Differential Overlap) (Dewar et al., 1977). MNDO is a valenceelectron self-consistent molecular orbital treatment which employs a minimal basis set of atomic orbitals and the NDDO approximation (Neglect of diatomic differential overlap) (Pople et al., 1965, Pople et al., 1967). Semi-empirical methods could contain hydrogen bond corrections to improve their quality (Korth et al., 2010, Korth, 2010). The corrections improve the accuracy of bond lengths as well as the angels between the atoms which form water dimmers.

The ab initio (DFT) (Hohenberg et al., 1964, Kohn et al., 1965) calculation was used within the SIESTA software package. All simulations have been done on standard KohnSham self-consistent density functional method. The Kohn-Sham equations were solved using generalized-gradient exchange-correlation functional approximation (GGA). Oneparticle problem is solved by linear combination of atomic orbitals (LCAO). Atomic pseudopotentials for hydrogen and oxygen atoms were taken from the web side of SIESTA developers (http://www.icmab.es/siesta/). Multiple-basis set has been used with polarization and diffuse orbital. Conjugate gradient method has been chosen for coordinate's optimization. For $a b$ initio simulations we have used computational cluster consisted of 16 individual nodes. Nodes are connected with infiniband network with high data transfer speed. Time demand of used computation methods is shown in Table 1 .

Table 1. Time demands in seconds for used computation methods. Dashed line represents extremely time consuming calculations which were not done.

\begin{tabular}{cccccc} 
& \multicolumn{5}{c}{ Computation method } \\
\cline { 2 - 6 } \begin{tabular}{c} 
Number of $\begin{array}{c}\text { Nater } \\
\text { molecules }\end{array}$ \\
\cline { 2 - 6 }
\end{tabular} & AM1 & PM3 & PM6 & $\begin{array}{c}\text { SIESTA } \\
\text { serial } \\
\text { version }\end{array}$ & $\begin{array}{c}\text { SIESTA } \\
\text { parallel } \\
\text { version }\end{array}$ \\
\hline 21 & $9.9 \mathrm{E}+01$ & $9.1 \mathrm{E}+01$ & $6.6 \mathrm{E}+01$ & $8.2 \mathrm{E}+04$ & $5.1 \mathrm{E}+04$ \\
33 & $5.6 \mathrm{E}+02$ & $4.4 \mathrm{E}+02$ & $3.0 \mathrm{E}+02$ & $2.9 \mathrm{E}+05$ & $1.6 \mathrm{E}+05$ \\
43 & $6.9 \mathrm{E}+02$ & $5.7 \mathrm{E}+02$ & $3.6 \mathrm{E}+02$ & ------- & $2.5 \mathrm{E}+05$ \\
51 & $1.4 \mathrm{E}+03$ & $8.4 \mathrm{E}+02$ & $7.2 \mathrm{E}+02$ & ------- & $4.7 \mathrm{E}+05$ \\
109 & $1.9 \mathrm{E}+04$ & $1.7 \mathrm{E}+04$ & $1.3 \mathrm{E}+04$ & ------ & ------
\end{tabular}

Results from all used computational approaches have been interpreted in the frame of radial distribution function $g(r)$ (RDF). RDF describes how the atomic density varies as a function of the distance $r$ from the origin (Madan et al., 1999). The position and number of peaks from RDF is crucial for the interpretation of a liquid(s) structure. RDF of simulated water systems can be compared with X-ray and neutron scattering experiment results, which are essential data about microscopic structure of water. 


\section{RESULTS AND DISCUSSION}

All used simulations gave regular radial distribution function for oxygen atoms $\left(g_{O O}(r)\right)$ in water. The position of first $g_{O O}(r)$ peak is the key feature for liquid water. Second and third peak indicates the residual ice structure in the liquid water. The position of these three peaks is compared with experimental results from X-ray scattering experiment (Hura et al., 2000).

It was shown that MM requires larger water system to obtain relevant RDF because small clusters have $g_{O O}(r)$ graph without evident peaks. Therefore, in Figure 1. only $g_{O O}(r)$ for large water clusters is shown.

First maximum of $g_{O O}(r)$ X-ray scattering data leads to the value of $2.75 \AA$. It can be seen that optimized water systems by molecular mechanic show the maximum for oxygenoxygen distance at $3.30 \AA$. This peak is broad and higher then experimental data. It indicates larger firs hydration shell of water molecules. The position of second and third peak could not be seen in Figure 1. The conclusion that follows from these findings is that MM optimisation only roughly interprets the structure of liquid water. It can be caused by the absence of the specific hydrogen bonding term in AMBER99 force field. This result should be considered before choosing the force field for combined QM/MM techniques (Hao et al., 2003, Murugan, 2011, Sakata et al., 2011).

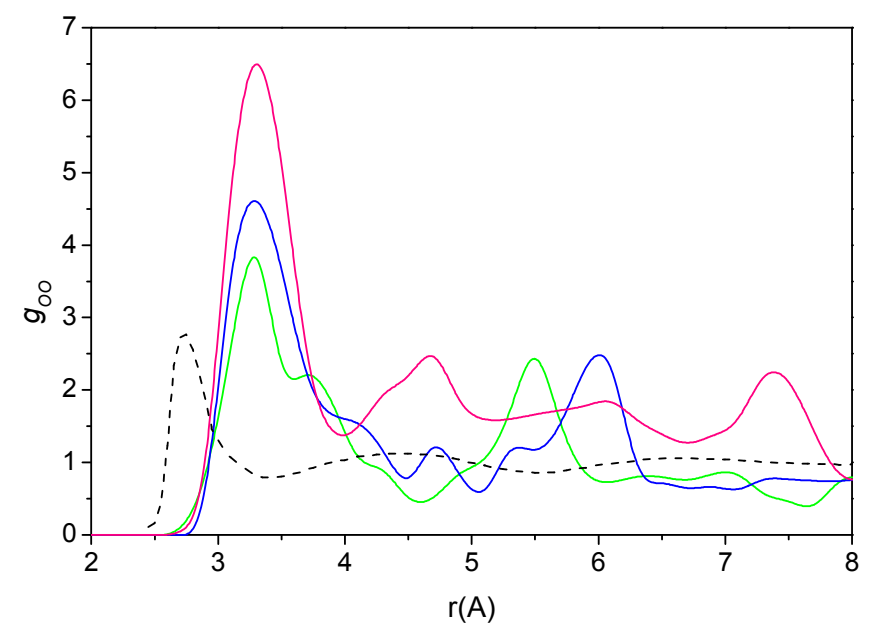

Figure 1. Radial distribution functions for 41 (green line), 51 (blue line) and 109 (pink line) water molecules in cube box. It was used MM optimisation with AMBER99 force field. X-ray scattering experiment data (dashed line) (Sakata et al., 2011).

Figure 2. shows $g_{O O}(r)$ of water systems after semi-empirical (AM1) optimisation. Position of the first peak $(2.70 \AA)$ for small clusters is in good agreement with experimental value. Large clusters have the first peak position little shifted towards the value of $2.90 \AA$. 
First peak represents the radius of first hydration shell of the water molecule. Second peak is slightly shifted towards the value of $5.00 \AA$. The value corresponds to second hydration spheres around water molecule. This sphere (experimental radius $4.50 \AA$ ) is typical for ice in hexagonal crystal structure (Soper, 2000, Fan et al., 2010, Vega et al., 2005).

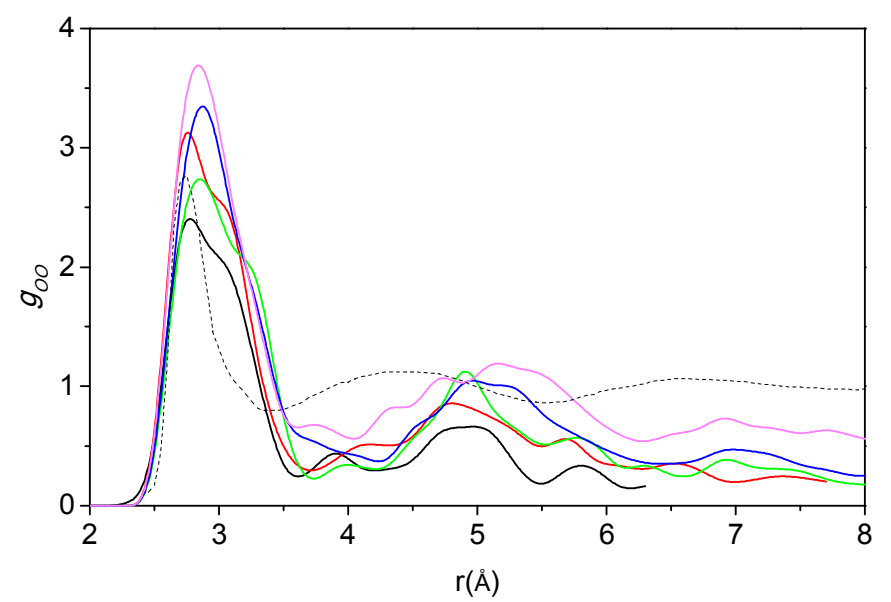

Figure 2. Radial distribution functions for 21 (black line), 33 (red line), 41 (green line), 51 (blue line) and 109 (pink line) water molecules in cube box. It was used semi-empirical optimisation with AM1 parameterisation. X-ray scattering experiment data (dashed line) (Sakata et al., 2011).

Results for water systems optimized by semi-empirical method with PM3 parameterisation are shown in Figure 3. The radius of the first hydration shell of water is $2.90 \AA$. This value was independent of the size of water system. The position of second characteristic peak for optimized water is at $4.75 \AA$ what is close to the experimental result obtained from X-ray scattering data. The graph of $g_{O O}(r)$ contains one more peak with the position $3.50 \AA$. This distance occurs in liquid water under high pressure or high temperature when the second hydration shell collapses on the shell of first neighbours (Urquidi et al., 1999). Extra peak, which is shown in Figure 3., is a systematic error of PM3 parameterisation and is independent on the size of cluster. 


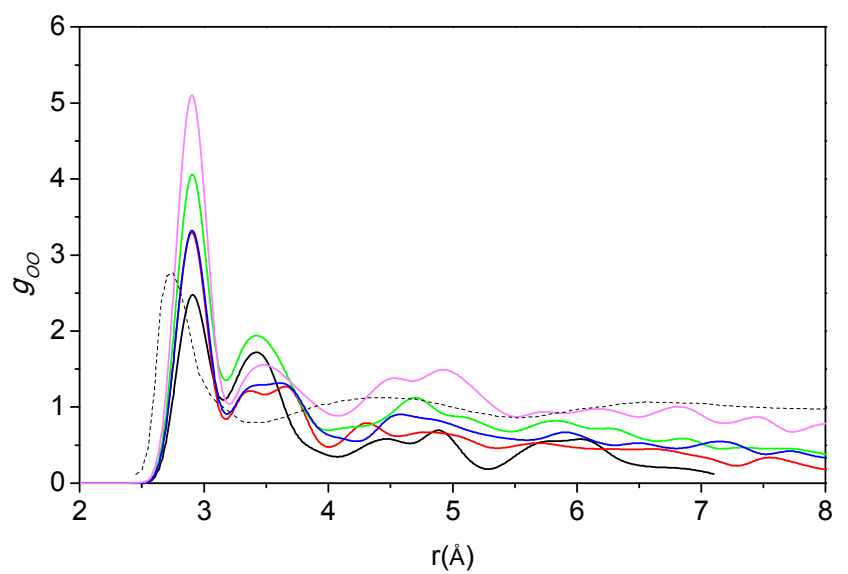

Figure 3. Radial distribution functions for 21 (black line), 33 (red line), 41 (green line), 51 (blue line) and 109 (pink line) water molecules in cube box. It was used semi-empirical optimisation with PM3 parameterisation. X-ray scattering experiment data (dashed line) (Sakata et al., 2011).

The best results we have achieved using recently published PM6 parameterisation. The position and shape of first $g_{O O}(r)$ peak was $2.70 \AA$ (Figure 4.). The shape of second peak was not very smooth however the broadness corresponds with the experiment.

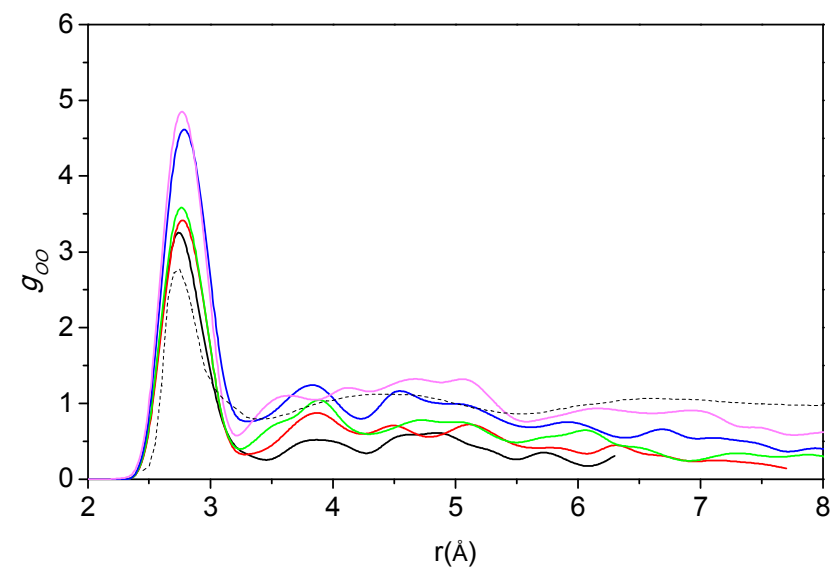

Figure 4. Radial distribution functions for 21 (black line), 33 (red line), 41 (green line), 51 (blue line) and 109 (pink line) water molecules in cube box. It was used semi-empirical optimisation with PM6 parameterisation. X-ray scattering experiment data (dashed line) (Sakata et al., 2011).

In Figure 5. we can see that the position and shape of first hydration shell for optimised clusters obtained with $a b$ initio DFT method is in good agreement with experimental data. 
The position of firs peak $2.90 \AA$ almost coincides with the reference result. Generally, second peak is well reproduced. Only the simulation with 21 water molecules has second peak slightly shifted towards the lower value of $4.15 \AA$. It is caused by too small number of water molecules in cluster. In the $a b$ initio simulation we have used GGA exchange functional. It is known that this approximation underestimate intermolecular interaction (Perdev et al., 1996). It can be the reason of getting poorer results for first hydration shell with DFT than with semi-empirical method (PM6) although ab initio is the most accurate approach.

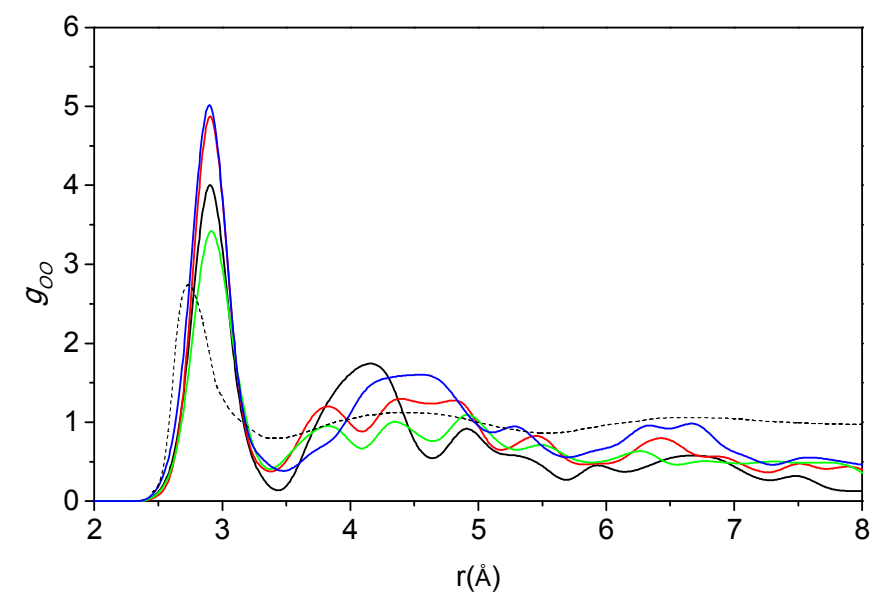

Figure 5. Radial distribution functions for 21 (black line), 33 (red line), 41 (green line) and 51 (blue line) water molecules in cube box. It was used ab initio DFT method. X-ray scattering experiment data (dashed line) (Sakata et al., 2011).

\section{CONCLUSIONS}

We have presented the comparison of different approaches with the aim to optimize water clusters. Optimizations for the water systems have been carried out employing molecular mechanic, semi-empirical and ab initio DFT method. The results are interpreted with the assistance of radial distribution function (RDF). Radial distribution function for oxygen-oxygen couple represents the oxygen density variations as the function of a distance $r$ from the origin (another oxygen atom). All results are compared with the experimental RDF taken from X-ray scattering experiment data (Sakata et al., 2011).

Molecular mechanic approach with AMBER99 force field is the simplest and fastest method. Interpretation of water structure is very inaccurate. MM requires large clusters to provide relevant RDF. Results with AMBER99 force field are poor, shoving the position of first hydration shell at $3.30 \AA$ against experimental value of $2.75 \AA$. 
Consecutively we have employed semi-empirical method. All used parameterisations (AM1, PM3 and PM6) provides relatively correct position $(2.7-2.9 \AA)$ of first hydration shell for water molecule according to experimental value. The reproducibility of second peak, which represents residual hexagonal ice structure, is poorer for AM1 and PM3 parameterisation $(5.00 \AA$ and $4.75 \AA$ ). From our results is seen that PM3 parameterisation gets RDF with systematic error. RDF contains extra peak with position of $3.50 \AA$, which indicates collapse of second hydration shell.

The best results we have got using PM6 parameterisation. The position and shape of first and second hydration shell is in very good agreement with experimental value. These positions are independent of the water cluster size. Further, the computation with PM6 is the fastest from all tested semi-empirical parameterisations (AM1, PM3, and PM6).

$\mathrm{Ab}$ initio method little underestimates intermolecular interaction in water clusters. The radius of first hydration shell $(2.90 \AA)$ is independent of the water cluster size. Second hydration shell is well reproduced in all clusters except small cluster with 21 individual water molecules. In this case the number of water molecules was insufficient for calculation and the position of second hydration shell is shifted towards the lower value of $4.15 \AA$. In spite of the fact that $a b$ initio DFT approach is the most accurate and time consuming from all tested methods we have got poorer RDF for all computed water clusters.

In conclusion, our results indicate advantage of "middle road" semi-empirical approach with PM6 parameterisation over AM1, PM3 and ab initio DFT approach.

\section{ACKNOWLEDGEMENTS}

This publication is the result of the project implementation: CENTRE II, ITMS code 26240120019, supported by the Research \& Development Operational Programme funded by the ERDF. The authors wish to thank the Comenius University (Grant No. $\mathrm{UK} / 86 / 2012$ ), for its financial support.

\section{REFERENCES}

Azam SS, Zaheer-Il-Haq Fatmi MQ. Classical and QM/MM MD simulations of sodium(I) and potassium(I) ions in aqueous solution. J Mol Liq 2010;153:95-100.

Bandad M, Alavi S, Nafaji B, et al. A new expression for radial distribution function and infinite shear modulus of Lennard-Jones fluids. Chem Phys. 2006;325:554-562.

Campo MG. Structural and dynamic properties of SPC/E water. Papers Phys. 2010;2:1-7.

Cordeiro MAM, Santana WP, Cusinato R, et al. Monte carlo investigations of intermolecular interactions in water-amide mixtures. J Mol Struct: THEOCHEM. 2006;759:159-164. 
Cornell WD, Cieplack P, Bayly CI, et al. A Second Generation Force Field for the Simulation of Proteins, Nucleic Acids, and Organic Molecules. J Am Chem Soc. 1995;117:5179-1597.

Dewar MJS, Thiel W. Development and use of quantum mechanical molecular models. 76. AM1: a new general purpose quantum mechanical molecular model. J Am Chem. Soc. 1977;99:4899-4907.

Dewar MJS, Zoebisch EG, Healy EF, et al. Development and use of quantum mechanical molecular models. 76. AM1: a new general purpose quantum mechanical molecular model. J Am Chem Soc. 1985;107: 3902-3909.

Fan XF, Bing D, Zhang JY, et al. Predicting the hydrogen bond ordered structures of ice Ih, II, III, VI and ice VII: DFT methods with localized based set. Comput Mater Sci. 2010;49:S170-S175.

Garrido NM, Queimada AJ, Jorge M, et al. Molecular simulation of absolute hydration Gibbs energies of polar compounds. Fluid Phase Equil. 2010;296:110-115.

Guillot B. A reappraisal of what we have learnt during three decades of computer simulations on water. J Mol Liq. 2002;101:219-260.

Hao H, Elstner M, Hermans J. Comparison of a QM/MM force field and molecular mechanics force fields in simulations of alanine and glycine "dipeptides" (Ace-Ala-Nme and Ace-Gly-Nme) in water in relation to the problem of modeling the unfolded peptide backbone in solution. Proteins: Structure, Function and Genetics 2003;50:451-463.

Head-Gordon T. Water Structure from Scattering Experiments and Simulation. Chem Rev. 2002;102:2651-2670.

Hohenb erg P, Kohn W. Inhomogeneous Electron Gas Phys Rev. 1964;136: B864-B873.

Hugosson HW, Laio A, Maurer P, et al. A comparative theoretical study of dipeptide solvation in water. J Comput Chem. 2006;27:672-684.

Hura G, Sorenson J M, Glaesert RM, et al. High-quality X-ray scattering experiment on liquid water at ambient conditions. J Chem Phys. 2000;113:9140-9148.

HyperChem (TM) Professional 7.51, Hypercube, Inc., 1115 NW 4th Street, Gainesville, Florida 32601, USA

Intharathep $\mathrm{P}$, Tongraar $\mathrm{A}$, Sagarik $\mathrm{K}$. Ab initio $\mathrm{QM} / \mathrm{MM}$ dynamics of $\mathrm{H} 3 \mathrm{O}+$ in water. J Comput Chem. 2006;27:1723-1732. 
Kohn W, Sham L. Quantum Density Oscillations in an Inhomogeneous Electron Gas. J Phys Rev. 1965;137:A1697-A1705.

Korth M, Pitonak M, Rezac J, et al. A Transferable H-Bonding Correction for Semiempirical Quantum-Chemical Methods. J Chem Theory Comput. 2010;6:344352.

Korth M. Third-Generation Hydrogen-Bonding Corrections for Semiempirical QM Methods and Force Fields. J Chem Theory Comput. 2010;6:3808-3816.

Kuhne TD, Krack M, Parrinello M. Static and Dynamical Properties of Liquid Water from First Principles by a Novel Car? Parrinello-like Approach. J Chem Theory Comput. 2009;5:235-241.

Madan B, Sharp K. Changes in water structure induced by a hydrophobic solute probed by simulation of the water hydrogen bond angle and radial distribution functions. Biophys Chem. 1999;78:33-41.

MOPAC2009, James J. P. Stewart, Stewart Computational Chemistry, Version 10.153W Accesed at http://OpenMOPAC.net

Murugan NA. Modeling Solvatochromism of a Quinolinium Betaine Dye in Water Solvent Using Sequential Hybrid QM/MM and Semicontinuum Approach. J Phys Chem. B 2011;115:1056-1061.

Ordejon P, Artacho E, Soler JM. SIESTA code written. Phys Rev B. 1996;53:1044110444.

Perdev JP, Burke K, Ernzerhof M. Generalized Gradient Approximation Made Simple. Phys Rev Lett. 1996;77:3865-3868.

Perez A, Marchan I, Svozil D, et al. Refinement of the AMBER Force Field for Nucleic Acids: Improving the Description of a/g Conformers. Biophys J. 2007;92:3817-3829.

Ponder JW, Case DA. Force Fields for Protein Simulations. Adv. Protein Chem. 2003; $66: 27-85$.

Pople JA, Beveridge DL, Dobosh PA. Approximate self-consistent molecular-orbital theory. V. Intermediate neglect of differential overlap. J Chem Phys. 1967;47:2026-2033.

Pople JA, Santry DP, Segal GA, Approximate self-consistent molecular orbital theory. I. Invariant procedures. J Chem Phys. 1965;43:S129-S135.

Ramachandra KI, Deepa G, Namboori K. Computational Chemistry and Molecular Modeling, Springer-Verlag, Inc. Berlin, 2008. 
Sakata T, Kawashima Y, Nakano H, Solvent effect on the absorption spectra of coumarin 120 in water: A combined quantum mechanical and molecular mechanical study. J Chem Phys. 2011;134:14501-14502.

SIESTA. Accessed at http://www.icmab.es/siesta/

Soper AK. The radial distribution functions of water and ice from 220 to $673 \mathrm{~K}$ and at pressures up to $400 \mathrm{MPa}$. Chem Phys. 2000;258:121-137.

Sorenson JM, Hura G, Glaeser RM, et al. What can x-ray scattering tell us about the radial distribution functions of water? J Chem Phys. 2000;113:9149-9162.

Stewart JJP. Optimization of parameters for semiempirical methods I. Method. J Comput Chem. 1989;10:209-220.

Stewart JJP. Optimization of parameters for semiempirical methods V Modification of NDDO approximations and application to 70 elements. J Mol Model. 2007;13:11731213.

Tunon I, Martins-Costa MTC, Millot C, et al. A coupled density functional-molecular mechanics Monte Carlo simulation method: The water molecule in liquid water. J Comput Chem. 1996;17:19-29.

Urquidi J, Cho $\mathrm{CH}$, Singh $\mathrm{S}$, et al. Temperature and pressure effects on the structure of liquid water. J Mol Struct. 1999;485-486:363-371.

Vega C, McBride C, Sanz E, et al. Radial distribution functions and densities for the SPC/E, TIP4P and TIP5P models for liquid water and ices Ih, Ic, II, III, IV, V, VI, VII, VIII, IX, XI and XII. Phys Chem. 2005;7:1450-1456.

Woods RJ, Tessier MB. Computational glycoscience: characterizing the spatial and temporal properties of glycans and glycan-protein complexes. Curr Opin Struct Biol. 2010;20:575-583.

Zhang S, Baker J, Pulay P. A Reliable and Efficient First Principles-Based Method for Predicting pKa Values, 1. Methodology. J. Phys. Chem. 2010;114:425-431.

Registered: February, 6, 2012

Accepted: July, 30, 2012
PharmDr. Roman Staník Comenius University in Bratislava Faculty of Pharmacy

Odbojárov 10 832 32, Bratislava

Slovak republic stanik@fpharm.uniba.sk 


\title{
POROVNANIE RÔZNYCH VÝPOČTOVÝCH METÓD PRE OPTIMALIZÁCIU
}

\section{ŠTRUKTÚRY VODY}

\author{
${ }^{1}$ Staník, R. - ${ }^{2}$ Ballo, P. - ${ }^{1}$ Benkovský, I. \\ ${ }^{1}$ Department of Pharmaceutical Analysis and Nuclear Pharmacy, Faculty of Pharmacy, Comenius \\ University, Bratislava, Slovakia \\ ${ }^{2}$ Department of Physics, Faculty of Electrical Engineering and Information Technology, Slovak \\ University of Technology, Bratislava, Slovakia
}

Porovnali sme niekol'ko výpočtových techník s ciel’om získat' radiálnu distribučnú funkciu (RDF), ktorá je vhodná na charakteristiku štruktúry vody. Menovite sme použili molekulovú mechaniku (AMBER99), semi-empirické (AM1, PM3, PM6) a ab initio (DFT) techniky. Ukázalo sa, že molekulová mechanika poskytuje vel'mi slabé výsledky vzhl'adom na RDF vody. Ab initio techniky, ktoré sú všeobecne akceptované ako vel'mi presné metódy, v prípade vody podceňujú medzimolekulové interakcie. Prekvapujúco, semi-empirická metóda S PM6 parametrizáciou poskytuje najlepšie výsledky v porovnaní s meraním RDF pomocou X-ray rozptylu.

Acta Pharm. Uni. Comen. LIX, 2012, p. 55 - 66 